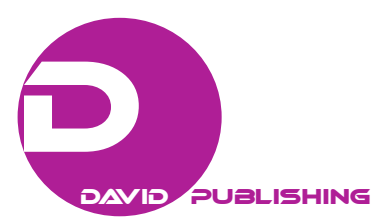

\title{
Marketing Strategies of Tourism Business for Male Homosexual Targets
}

\author{
Wichayanunth Porkha \\ University of Phayao, Bangkok, Thailand
}

\begin{abstract}
The acceptance of tourism businesses for gays is still dubious. Businesses designed for gays are still grey businesses. The image problem of tourism businesses for gays needs to be corrected, so that entrepreneurs will feel comfortable to launch tourism businesses for gays only or to do tourism businesses that are gay-friendly. This is the genesis of the research conducted among gay men in Bangkok. The number of male homosexuals in Bangkok is increasing, and pink dollars are also increasing. This study is a mixed research-quantitative and qualitative. A structured questionnaire was distributed among 400 male homosexuals in Bangkok, and experts in various fields were interviewed. The study reveals that most gays appear as normal men; very few of them look feminine or are transvestites and transgender. As for tourism, they prefer going to gay-friendly places to going to tourism businesses for gays only. The findings indicate that Thailand should develop tourism businesses for gay target groups because Thailand has a reputation of being a Gay Paradise. The public sector should be aware of the significance of gay target groups to capture a share of pink dollars. There should be a social campaign to create receptivity of sexuality diversity in order to induce entrepreneurs to invest in gay friendly tourism businesses and to make gay customers feel comfortable to use the services. If the entrepreneurs are gays, there are chances of being successful. Based on the findings, the researcher has formulated a strategic paradigm framework entitled DEPTH.
\end{abstract}

Keywords: tourism business, gay customers, marketing strategy

\section{Introduction}

Since the beginning of new millennial, societies are more open to sexuality diversity. However, gay people still have problems in using tourism services because some businesses express hostility towards gay customers. Some non-gay customers express the feeling that they do not want to travel or do activities with gay people. Despite this prejudice, more gay people have come out of the closet and media pay more attention to them. Publics are exposed to more and more social and legal issues concerning gay life styles, and the trend looks promising. Gay customers have high purchasing power in tourism businesses. They are looking for tourism businesses that are more gay-friendly. They want to see that entrepreneurs are receptive to sexuality diversity. Nonetheless, some of them do not feel comfortable when using tourism services. Consequently, they do not feel confident to express their true sexuality. Recreational activities of gay people are still under pejorative criticism among some heterosexual people; thus, gay people do not feel comfortable to participate in recreational

Wichayanunth Porkha, Ph.D., doctor of Philosophy (Tourism and Hotel Management), College of Management, University of Phayao, Bangkok, Thailand.

Correspondence concerning this article should be addressed to Wichayanunth Porkha, College of Management, University of Phayao, 55 Wave Place Building 8th floor, Lumpini, Pathumwan, Bangkok 10330, Thailand. 
activities of tourism. In a modern legal and social context, tourism businesses designed as exclusive businesses for gay customers or as gay-friendly businesses have high marketing potential for three major reasons: (1) societies are more open to sexuality diversity; (2) more gay people have come out of the closet; and (3) media pay more attention to issues of sexuality diversity.

\section{Research Problems}

(1) Should tourism businesses in Thailand develop services exclusive for gay customers or cultivate gay-friendly attitudes among employees?

(2) Do tourism businesses for gay customers have high potential in Thailand?

(3) What are obstacles in developing gay-friendly tourism businesses?

(4) What is the role of the Government in this development?

(5) What is a good marketing strategy for gay-friendly tourism business?

(6) What are success factors?

(7) Should there be a social campaign to create receptivity of gay-friendly tourism businesses?

\section{Research Objectives}

(1) To find out an approach to develop marketing strategies for gay-friendly tourism businesses;

(2) To leverage the phenomenon of pink dollar growth in order to gain high shares of pink dollars that are growing world-wide;

(3) To create an image manifesting that Thailand is a country that supports equality among people with diverse sexualities.

\section{Research Methods}

This is a mixed research, using both qualitative and quantitative methods. The qualitative method was conducted by using in-depth interviews with experts in various fields, including public officers working on tourism industry, private entrepreneurs doing tourism businesses for gay customers, law enforcement officers, social campaign professionals, human right activists, and scholars in the fields of tourism, marketing, and marketing communications. The findings were analyzed and synthesized into 10 topics.

The quantitative method was conducted as a survey research with a structured questionnaire distributed among convenient samples of 400 male homosexuals in Bangkok. The questions were designed to learn about their sexuality, their tourism behaviours, their psychological emotion when travel or do activities with non-gay customers, and how confident they were when using tourism services along with non-gay customers. The question also asked whether they would like to have a social campaign that created receptivity for gay-friendly tourism businesses.

\section{Quantitative Research Findings}

\section{Appearance and Tourism Behaviours}

A majority of male homosexual in Thailand appeared as normal straight guys; very few of them looked feminine or were transvestites and transgender. There were more transvestites than transgender. Some of them were bisexuals. There were more Y generation cohorts than older cohorts. A majority of them travelled more than four times a year, and they preferred driving cars to other modes of travelling. They preferred travelling 
with friends and families to using services of tour agencies. They look for tourism information on social media to decide where to go. They also used social media to look for famous local restaurants when they dined in their destinations. They liked sightseeing tours, shopping tours, and visiting tourism attraction sites. They did not care much about sports tours, agricultural tours, and theme parks.

\section{Psychological Setup and Desires}

Most of them did not feel intimidated when other people know that they were gay. While gay people who looked feminine felt uncomfortable when being among non-gay companions, those who appeared straight did not feel the same way. As they looked like normal straight people, they did not feel awkward being among non-gay people. This indicated that more gays were more confident in expressing their true sexualities. Nonetheless, they still would like to have some tourism businesses that were designed exclusively for gays. Most of them would like to have a social campaign designed to cultivate receptivity of sexuality diversity, so that they could be customers of gay-friendly tourism businesses without running into people who had prejudice against gay people. They believed that if there were such a social campaign more people would become more gay-friendly, and they could travel and do recreational activities with non-gay companions. When being asked whether they would prefer tourism businesses designed exclusively for gays or tourism businesses designed for people with diverse sexualities with gay-friendly attitudes. They preferred the latter to the former.

\section{Perception of the Potential of Tourism for Gays in Bangkok}

The respondents believed that Bangkok was a Gay Paradise because people were more open to diverse sexualities than people in other cities like New York, Sydney, and Berlin. They would like to have a social campaign because they would like non-gay people to accept that tourism businesses for gays were legal and ethical, and they would feel more comfortable to use the services.

\section{Qualitative Research Findings}

The findings from in-depth interviews with experts of various fields related to the development of tourism businesses were analyzed and synthesized into 10 topics as follows.

\section{Potential}

Thailand has a great potential for tourism businesses for gay customers. Thailand should develop tourism businesses designed exclusively for gay customers, and businesses that were developed for customers of any sexuality should be more gay-friendly because gay target groups were large segments to capture. Despite the fact that the gay segment was a niche market, it was substantial enough and had high growth potential. Gay customers had high purchasing power. Tourism businesses for gay customers had high potential because Thai people were open to sexuality diversity. The development of tourism businesses for gay customers would make Thailand gain high shares of pink dollars, which had been growing globally, and it would also create a good image for Thailand, which would be perceived as a country upholding equality among different sexualities.

\section{Chances of Success}

Tourism businesses for gay customers in Thailand are likely to be successful. A chance for tourism businesses for gay customers to be successful was very high. It was mandatory that entrepreneurs have gay customer insights, and pay attention to cultivating gay-friendly attitudes among employees. At the same time, it was essential that there is a social campaign persuading straight people to be more open and receptive to 
diverse sexualities, so that gay people would feel more comfortable, when using tourism businesses designed to be catering to gay customers.

\section{Obstacles}

Ambiguity of laws and social prejudice are two main factors that impede the development of tourism businesses for gay customers in Thailand. Two main obstacles were: (1) a dubious interpretation of laws concerning businesses for gay customers; and (2) social prejudice against gays, which resulted in the government lacking a clear policy on the issue, and entrepreneurs being reluctant to clearly communicate that their businesses were catering to gay customers. As some gay people did not feel comfortable when using services of tourism businesses designed for gay customers, a social campaign to reduce social prejudice against gay people was desirable. When the prejudice was reduced the government would feel assured to launch a policy concerning the development of tourism businesses for gay customers, entrepreneurs would also feel assured to invest in this type of business, and gay people would feel more comfortable when using services of this type of business.

\section{Preference of Gay-friendly Business to Business Exclusively for Gay Targets}

Tourism businesses for general target groups that are gay-friendly are preferred to tourism businesses designed exclusively for gay customers. When being asked to choose between developing tourism businesses designed exclusively for gay customers and tourism businesses for people of all inclinations of sexuality that were gay friendly, the informants gave different answers. Some chose to develop tourism businesses designed exclusively for gay customers because they believe that gay people would not want to travel or do activities with straight people. They believed that this type of business would be more focused. Though this market was a niche segment, it was sizable enough, and it had high growth potential. The others chose to develop gay-friendly tourism businesses because this type of business would be a mass market with larger customer bases and higher profitability. It was believed that gay entrepreneurs would have better chances of being successful because they had better customer insights.

\section{Good Practices}

Entrepreneurs must be subtle in running tourism businesses for gay customers, so that they will not defy social norms and straight people. When doing tourism businesses for gay customers, entrepreneurs should not do anything that would defy social movements because tourism businesses for gay customers had not yet been established. Locations must be well selected, not to be close to schools or religious sites. Marketing communication messages must be subtle. Message and channel strategies must be well considered, so that they would not appear defying social norms and decencies. Cultivating gay-friendly culture in organization was a must, so that gay customers would feel comfortable interacting with employees who were service providers.

\section{Roles of the Government}

The government should no longer ignore the existence of gay customers in tourism industry; on the contrary, they should try to gain insights about this segment of the market, so that they can have a clear direction of support. The government had to be aware of the existence of this segment, and public officers should learn values and life styles of gay people. They should realize that the number of gay people was increasing, and they had high purchasing power. Law officers must provide clear and definite interpretation of all legal acts pertaining to gay businesses and activities. Public officers should try to understand gay people's 
tourism behaviors and activities, they must rid themselves of prejudice against gay people. The government must launch a policy that promotes tourism businesses for gay customers by looking at this type of business as an industry to promote and support. The government should also provide a substantial budget to organize and publicize tourism activities for gay people.

\section{Marketing Communications}

Messages and channel strategies if marketing communications must be well considered, so that they will not offend general public. Marketing communications of tourism businesses for gay people were acceptable. Messages must be subtly created, so that they would not offend publics. Marketing communications for tourism businesses should be disseminated on line through various forms of social media. If mass media were selected, they should be the ones with gay targets. Mass media for general targets should not be used, so that the campaigns did not appear defying and offending public norms.

\section{Opponent Groups}

Despite the fact that publics are more open to diversity of sexuality, people who are strongly religious still resent the existence of homosexuals. In Thailand, the resentment might not be intense, but there were some radicals who might launch anti-gay activities. In order to prevent any anti-gay incident, entrepreneurs and gay customers must comply with rules of ethics and decency. They should not excessively expose their sexuality, which was regarded as "abnormal” by a certain number of people.

\section{A Need for Social Campaign}

A social campaign to create receptivity of tourism businesses for gay customers is not necessary. Most of the key informants of this study did not see a need for a social campaign to persuade people to accept tourism businesses for gay customers. They felt that if there was such a campaign, it might provoke straight people to launch a campaign against tourism businesses for gay customers. Should there be a social campaign, it might be more appropriate to launch a campaign to persuade publics to accept sexuality diversity.

\section{Customer Insights Are Essential}

Customer insights are required for tourism businesses for gay customers to be successful. Entrepreneurs must have good insights of gay customers. They must understand gay customers' needs, wants, tastes, preferences, and expatiations that dynamically evolved. They must pay attention to cultivating gay-friendly attitudes among their employees, so that they could be assured that they were running gay-friendly businesses. Employees working in gay-friendly tour businesses must make gay customers trust them, feel assured that friendly services would be provided, and feel comfortable as they would not be treated with prejudice against homosexuals.

\section{Discussion}

Thailand has high potential to develop tourism businesses for gay customers. These businesses could either be businesses designed exclusively for gay customers or businesses for general targets with gay-friendly attitudes and behaviours among employees. Though gays in Thailand today appear manly like straight people, and do not look feminine, they still want to see a social campaign persuading people to accept tourism businesses for gay customers. They want to feel assured and comfortable when using services of this type of business. As the number of gays in Thailand has been increasing in recent years, and gay foreigners regard Thailand as a Gay Paradise, public sectors and private entrepreneurs should see that it is important to develop 
tourism business for gay customers. This type of business has high potential to be successful. Not only does it contribute to economic growth of the country, but it will also create for Thailand an image of a country with equal rights for people with different sexualities. In formulating marketing strategies of tourism businesses for gay targets, the following factors must be well considered:

- Increase a higher share of pink dollars: Thailand should seriously consider developing tourism businesses for gay customers to build revenues from presently growing pink dollars around the world.

- Leverage Thailand's competitive advantages: Thailand has competitive advantages in the arena of tourism businesses for gay customers because Thailand has many forms of tourism catering to both Thai and foreign tourists. Thailand is one of top destinations popular among tourists of many countries. Thailand is perceived to be a Gay Paradise by gay tourists of many countries.

- Gain supports of NGO's of human rights: Despite the fact that there might be some hindrances obstructing the development of tourism businesses for gay customers in Thailand, the problem can be dissolved because the law stating equal right for people of all sexualities has already been passed and promoted by NGO's of human right.

- Provoke government's participation and supports: Other than tourism businesses for gay customers, the government should host and provide budget for special gay events, and they should be held as national events to promote tourism of Thailand.

- Be subtle with communication campaigns: When they are tourism businesses for gay, there should be appropriate marketing communications to make gay targets aware of the businesses. It should be noted that a marketing communication campaign must be executed subtly. Messages should not contain sexual implications. They should not be too aggressive and defy social norms. The channels should be social media. Should mass media be selected, they should be media that are intended to capture gay audience niche.

- Use media for gay targets as channels of communication: Products and services with gay target groups should be sponsored of media for gay audiences. They should not worry that their brand images will be jeopardized by doing so. On the contrary, they should believe that businesses that support gay media are businesses that are receptive to sexual diversity, which will help them gain supports from gays, their friends, and their families.

- Cultivate gay-friendly attitudes and behaviours among human resources: If entrepreneurs who invest in tourism businesses for gay customers are gays, chances of being successful will be greater. Entrepreneurs of this type of tourism business must cultivate gay-friendly attitudes, behaviours, and expressions among their employees as parts of corporate culture. Their gay-friendly behaviours must be inside-out expressions. External behaviours are manifestations of their internal feelings. They do not have any resentment towards gays; on the contrary, they respect sexual diversity.

- Exploit the fact that publics in Thailand are receptive to sexual diversity: It is fortunate for Thailand to be populated by open-minded people who are receptive to sexual diversity; thus, the development of tourism businesses for gay customers will not face severe opposition. Because of this incident, tourism businesses for gay customers in Thailand when being taken serious will be growing without opposing radical activists. Consequently, entrepreneurs will feel confident in investing in this type of business, the government will feel comfortable in launching policies and projects to promote tourism businesses for gay customers. It is essential that the Office of National Economic and Social Development Board must be aware of the existence of LGBT groups, they must realize that this target segment has been growing for quite some time, and the segment can 
contribute to national economic growth. Board members must try to profoundly understand the phenomenon of pink dollars. They should not have any resentment against these groups; on the contrary, they should try to grasp insights of these groups to understand their values and life styles in order to come up with right products and services catering to LGBT target groups. Not only are products and services in tourism businesses developed, but also products and services for other industries.

- Clarify the interpretation of legal issues: When tourism businesses for gay customers are growing, interpretation of laws must be made crystally clear. Law enforcement officers should be definite about what businesses are legal or illegal. In the past, tourism businesses for gay customers, such as hotels, spas, fitness centres, bars, and shows, were raided by police officers and accused of running illegal businesses. Many times, the accusations were false; the police found nothing illegal. Nonetheless, images of the enterprises had been damaged before the truth came out. Many gay customers do not feel assured to use services of this type of business for fear that they might be at the scene of police raids. If the interpretation of law is not clear, there might be hindrances obstructing the growth of tourism businesses for gay customers.

- Operate tourism for gay targets subtly, do not be too aggressive: It is imperative that tourism business for gay customers must be executed subtly. They must be decent and ethical businesses. There should be no sexual implications, which is an image of tourism businesses for gay at present. In order to be successful, entrepreneurs who invest in this type of business must be aware of this current image, and try to dissolve it. At the same time, gays who use services of these businesses should not have any intention to use the places for any sexual actions.

- Pay close attention to the issues of image and reputation: Image and reputation are key success factors for tourism businesses for gay customers; thus, both entrepreneurs and customers must co-create good image and reputation for the businesses. They must help get rid of public prejudice against homosexuality, so that gay customers will feel comfortable to use services. That will bring about many rendezvous destinations for gay people. Gay customers feel comfortable to hang around at those place; publics look at them without prejudice. Consequently, Thailand gains a reputation of being a land of equal right for people of diverse sexualities, a land of freedom, and a land of liberals. Receptivity of sexual diversity is not just what is stated in laws, but it is actually practiced by most citizens of the county. The reality is empirically manifested, and Thailand will uphold the image of being a Gay Paradise perceived by gays of many countries. All of the aforementioned factors will create competitive advantages in tourism industry for Thailand at a global level.

\section{Recommendations}

As a result of the findings of this research, a marketing strategic plan for tourism businesses for gay customers in Thailand has been formulated as follows:

Mission: Upholding equality among diverse sexualities in tourism industry to enhance competitiveness of Thailand's tourism industry.

Visions: Thailand becomes a leading destination for LGBT tourists with gay-friendly tourism businesses;

Policy: Running social campaigns to create receptivity to sexual diversity, so that people with different sexualities can travel and do activities together peacefully.

C-PEST Analysis: An analysis of environments is as follows:

Competition: European countries, Australia, and the U.S. have developed tourism businesses for gay customers for quite some time, and most of tourism businesses in those countries are gay friendly. 
Politics: The law that ratifies equality among diverse sexualities was passed on September 9, 2015, and now it is effective.

Economics: Many research findings indicate that gays travel more frequently than straight people, and they tend to be big spenders.

Socio-culture: Society is now more open to sexual diversity. More gays have out of the closet. However, some of them feel uncomfortable being around straight people and are afraid that some straight people might have prejudice against them.

Technology: At present, most people are cohorts of digital generation; they use tablets and smart phones to search for tourism information. They also connect and communicate with their virtual friends on social media.

SWOT Analysis: Internal and external analyses of Thailand's tourism businesses for gay customers are as follows:

Strengths: More people in Thailand are open to sexual diversity, and more gay people have come out of the closet. More tourism businesses have become gay-friendly, and some of them are designed exclusively for gay customers.

Weaknesses: There are still too few tourism businesses for gay customers because of ambiguity of laws, resulting in investors being reluctant to invest in this type of business, and some gay people are not confident in using services of the businesses.

Opportunities: Social receptivity to sexual diversity enhances chances of being successful for tourism businesses for gay customers.

Threats: Despite the law ratifying equality among diverse sexualities, there are some people who have prejudice against homosexuality. This could be a hindrance obstructing this type of business to be successful.

Strategic Issues: Derived from the research findings, a strategic paradigm of how to develop tourism businesses for gay customers has been formulated under a title "DEPTH", signifying that entrepreneurs who run this type of business must have "deep" insights of gay customers.

D: Strategic process consists of 4 D's.

Discovery: Having good insights of gay tourists is a must.

Development: Developing gay-friendly businesses must put an emphasis on employees' behaviours and expressions.

Delivery: There must be marketing communication campaigns to create awareness and give accurate information about this type of business to create social receptivity, and assure gay people to confidently use services.

Diversity: There must be a process to cultivate positive attitudes towards sexual diversity, and create gay-friendly ambience.

E: Strategic move consists of 4 E's.

Education: There must be training sessions to educate employees on gay behaviours, attitudes, and other psychological factors.

Enculturation: Entrepreneurs must cultivate gay-friendly working styles and values among employees, so that they are gay-friendly at all touch points.

Egalitarianism: Employees must manifest the belief in equality among diverse sexualities in their interaction with gay customers at all touch points. 
Ethics: Entrepreneurs and employees should regard receptivity to sexual diversity as a part of good governance and ethical conducts.

P: Strategic marketing mix consists of 9 P's.

Principles: Having right principles is a good foundation of other marketing mixes

Product: Tourism businesses designed exclusively for gay customers are not really necessary, because gay people prefer using gay-friendly services to using services designed exclusively for gay customers.

Price: Prices of tourism services for gay customers should be moderate to high because many of them are big spenders.

Place: At present, tourism businesses for gay customers are in concealing places that are not safe and hard to access. When society is more open to sexual diversity, this type of business should be located at more open and easily accessible places, so that they will be safer than before.

Promotion: There must be marketing communication campaigns to create awareness of tourism businesses for gay customers with subtle messages without any sexual implications, and channels used in the campaigns should be niche media with gay audiences.

Public Relations: Launching social campaigns to create public receptivity to sexual diversity is a must, in order to assure entrepreneurs that it is socially acceptable to invest in gay-friendly tourism businesses, and to make gay customers feel comfortable when using services.

People: Employees working with gay-friendly tourism businesses should have gay-friendly attitudes and behaviours, respect sexual diversity, and have profound insights of gay people’s behaviours and psychological setups.

Process: When having transactions with gay customers, employees take precaution not to have any discrimination and prejudice against gay customers. The process used for gay customers should be the same as the one used for straight customers.

Physical Evidence: Gay customers must be allowed to use all facilities provided at business premises in the same way as straight customers are allowed; there should be no discrimination.

T: Strategic Changes: Changes are bedrocks to develop tourism businesses for gay customers because at present, a lot of people don't perceive that this segment can have a significant contribution to Thailand's economy. This perception must be changed. The government must admit that this segment truly exists, and it can become competitive advantages of Thailand's tourism industry. Changes consist of 2 T's as follows:

Training: There must be training classes to educate employees on gay life styles and values. Employees must be cultivated to have gay-friendly attitudes and learn how to behave appropriately towards gay customers. They should also learn how to show respect for sexual diversity, and not discriminatively treat gay customers.

Transformation: After employees have gone through training courses, transformation of corporate culture must be vividly manifested in employees’ behaviours, attitudes, and expressions.

Strategic Achievement: To determine effectiveness of the strategic development, three phenomena should be witnessed.

Harmony: Tourists of diverse sexualities travel and have activities together peacefully and happily. Gays and straight people feel comfortable to use services of the same tourism businesses. People with different sexualities respect each other.

Human Rights: Entrepreneurs, employees in tourism industry, and general public uphold human rights, and believe in equality among people with different sexualities. 
Human Value: All publics are receptive to sexual diversity. They are well aware of different behaviours and psychological setups among people with different sexualities. They do not perceive homosexual people as second class human being inferior to straight people.

As the aforementioned paradigm has been derived from solid findings of this research, it is safe to say that a strategic development of tourism businesses for gay customers within the framework of the paradigm should be considered to be thorough and should enhance competitiveness of Thailand's tourism industry.

\section{References}

Chalormyod, S. (2008). An approach to drive protective measures to prevent Bangkok ran gay from being assaulted. Thesis Rejabhat Suan Dusit, Bangkok.

Cohen, L. E., \& Felson, M. (1979). Social change and crime rate trends: A routine activity approach. American Sociological Review, 44, 588-607.

Danthamrongkul, W. et al. (2004). Social network and sexual relations among male homosexuals in Bangkok. Institute of Medical Science, Chulalongkorn University, Bangkok.

Felson, M., \& Clarke, R. V. (1998). Opportunity makes the thief practical theory for crime prevention. London: Crown.

Foster, D. (1985). Travel and tourism management. London: England.

Frank, P. (2004). Criminological theory. New Jersey: Pearson Prentice-Hall.

Gagnon and Simond. (1967). Out in theory: The emergence of lesbian and gay anthropology. USA: University of Illinois.

Guaracino, J. (2007). Gay and lesbian tourism. USA: Burlington.

Humphreys, L. (1970). Tearoom trade: Impersonal sex in public places. London: Duckworth.

Ingkawat, K. (1999). Lifestyle, purchasing behavior and media exposure of male homosexuals (Gay) in Bangkok metropolis. Thesis, Chulalongkorn University, Bangkok.

Jackson, P. A. (1995). Dear uncle go male homosexuality in Thailand. Bangkok: Bua Luang.

Kelyajti, S. (2003). An analysis of sexual deviant behaviors among the youth in the globalization era. Thesis, Mahidol University, Nakhonpathom.

Kotler, P. (2010). Marketing for hospitality and tourism. USA: Chicago.

Naksingha, P. (2005). Gay: Identity development and sexual lifestyle. Thesis, Thammasat University, Bangkok.

Nithiubat, C. (2003). Communication for self disclosure of male homosexuals. Thesis, Chulalongkorn University, Bangkok.

Romjumpa, T. (2002). Discourses on "gays” in thai society, 1965-2001. Thesis, Chulalongkorn University, Bangkok.

Rubin, G. S. (1993). Thinking sex: Note for a radical theory of the politic of sexuality. Great Britain: Routledge.

Siegal, L. J. (2008). Criminology tenth edition. Canada: Thomson Wadworth.

Smith, V. L. (1989). Hosts and guests: The anthropology of tourism. USA: New York.

Thailand Tourism Authority. (2013). TOT promote Thailand as destination for LGBT. http://www.siamintelligence.com/go-thai-be-free-gay-lesbian-thailand/

Wheeler-Quinnell, C. (2010). How to market to gay consumer. London: Stonewall. 